\title{
Successful Treatment of Refractory Candidal Granuloma by Itraconazole and Terbinafine in Combination with Hyperthermia and Cryotherapy
}

Heli Yang $\cdot$ Xiaoxi Xu $\cdot$ Xin Ran $\cdot$ Yuping Ran

Received: March 14, 2020 / Published online: May 14, 2020

(c) The Author(s) 2020

\section{ABSTRACT}

Candidal granuloma is a rare and refractory disease in clinical practice, usually reported in immunocompromised patients. We report a 57-year-old man who presented with candidal granuloma caused by Candida tropicalis. The diagnosis was confirmed according to histopathology and molecular identification. Prolonged duration of initial antifungal therapy did not obtain satisfactory improvement. Finally, the refractory disease was successfully treated by itraconazole and terbinafine in combination with hyperthermia and cryotherapy. The "blackish-red dot" dermoscopic sign of the verrucous granuloma gradually resolved during the treatment.

Keywords: Blackish-red dot sign; Candida tropicalis; Candidal granuloma; Cryotherapy; Dermoscopy; Hyperthermia; Itraconazole; Terbinafine

Digital Features To view digital features for this article go to https://doi.org/10.6084/m9.figshare.12190824.

H. Yang $\cdot$ X. Xu $\cdot$ X. Ran $\cdot$ Y. Ran $(\bowtie)$

Department of Dermatovenereology, West China

Hospital, Sichuan University, Chengdu, China

e-mail: ranyuping@vip.sina.com

\section{Key Summary Points}

A 57-year-old man presented with multiple verrucous plaques for 8 years; he was diagnosed with candidal granuloma caused by Candida tropicalis based on histopathology and molecular identification.

The patient did not respond well to longterm treatment only with terbinafine or itraconazole; however, efficacy was achieved using itraconazole and terbinafine in combination with hyperthermia and cryotherapy.

Notably, the blackish-red dot sign of the verrucous granuloma observed under dermoscopy gradually resolved during the treatment.

\section{INTRODUCTION}

In recent years, the incidence of Candida infection has increased in immunocompromised patients [1]. Although C. albicans remains the leading pathogenic agent of clinical primary or secondary infections, infections caused by nonCandida albicans, especially C. tropical, are also 
increasing [2, 3]. C. tropicalis mainly causes superficial infections and candidemia [4]. Candidal granuloma is an extremely rare manifestation of $C$. tropicalis infection. Herein, we report a case of refractory candidal granuloma successfully treated in combination with antifungal therapy, hyperthermia and cryotherapy. Informed written consent was obtained for the patient to publish the article and their images.

\section{CASE PRESENTATION}

A 57-year-old Chinese man with a known history of hypertension and stroke presented to our department for multiple plaques on his waist, right thigh and face in May 2019. Multiple verrucous plaques had been developing gradually on his waist and right thigh for 8 years without any apparent reason. He did not seek treatment for his lesions until 18 months ago; two continuously expanding plaques developed on his face with severe pruritus (Fig. 1a1, b1). He had been diagnosed with a subcutaneous fungal infection and treated with oral terbinafine $250 \mathrm{mg} /$ day and topical povidone-iodine for 5 months. However, the lesions did not improve. Hence, the therapeutic regimen was replaced by oral itraconazole $200 \mathrm{mg} /$ day for another 11 months. Lesions on the waist and right thigh partially improved but not those on the face.

Physical examination revealed two well-defined, regularly shaped, erythematous plaques with hyperkeratotic crusts, measuring $5 \times 5 \mathrm{~cm}$ and $10 \times 10 \mathrm{~cm}$, on his cheeks. The superficial lymph nodes, liver and spleen were normal to palpation. Chest auscultation was clear. Serum electrolytes, liver, renal function, antinuclear antibodies, and rheumatoid factors were within the normal range. HIV, syphilis, tuberculosis and tumor test results were negative. Blood tests indicated decreased lymphocyte counts (CD3, 481 cells/ $\mu \mathrm{l}$, normal range: $941-2226$ cells $/ \mu \mathrm{l}$; CD4, 295 cells $/ \mu l$, normal range: 471-1220 cells/ $\mu \mathrm{l}$; CD8, 164 cells/ $\mu \mathrm{l}$, normal range: 303-1003 cells/ $\mu \mathrm{l})$. Dermoscopic manifestation (JEDA, Nanjing, China) of the verrucous granuloma revealed telangiectasia, yellow proliferative scales tightly adhering to the skin and the blackish-red dot sign on an erythematous base (Fig. 1c1).

Although microscopic examination and fungal culture of the crusts were all negative, the pathologic findings provided evidence for definitive clinical diagnosis. A skin biopsy exhibited parakeratosis, pseudoepitheliomatous hyperplasia in the epidermis and dense neutrophilic and multinucleated giant cells in the dermis (HE) (Fig. 2a). Abundant short hyphae and yeasts in the stratum corneum (PAS and GMS) were also observed (Fig. 2b, c).

Molecular verification was subsequently performed to identify the fungal elements, and genomic DNA was extracted from paraffin-embedded tissue by the phenol-chloroform extracting method. The amplification of the ITS (internal transcribed spacer) rDNA region was performed through PCR using primers pair ITS1 and ITS4 in a $25-\mu$ l reaction system containing $12.5 \mu \mathrm{l}$ Taq polymerase (TaKaRa, Japan), $6.5 \mu \mathrm{l}$ $\mathrm{ddH}_{2} \mathrm{O}, 2 \mu \mathrm{l}$ of each primer $(10 \mu \mathrm{M})$ and $2 \mu \mathrm{l}$ rDNA. Amplification was performed as follows: $95^{\circ} \mathrm{C}$ for $4 \mathrm{~min}$, followed by 35 cycles consisting of $94{ }^{\circ} \mathrm{C}$ for $45 \mathrm{~s}, 52^{\circ} \mathrm{C}$ for $15 \mathrm{~s}$, and $72{ }^{\circ} \mathrm{C}$ for $2 \mathrm{~min}$, with a delay at $72{ }^{\circ} \mathrm{C}$ for $10 \mathrm{~min}$. PCR products were sent to The Beijing Genomics Institute (Beijing, China) for direct sequencing. Compared with the GenBank database, our sequence displayed $100 \%$ similarity with Candida tropicalis. Then, we identified the fungi as Candida tropicalis and submitted the sequence to GenBank under accession no. MN171542.

Finally, the diagnosis of candidal granuloma caused by Candida tropicalis was confirmed based on clinical manifestation, molecular investigation and histopathologic examinations. The patient was treated with oral terbinafine $250 \mathrm{mg} /$ day, itraconazole $200 \mathrm{mg} /$ day and topical application of naftifine-ketoconazole cream. To achieve the desired effect, topical application of naftifine-ketoconazole cream followed by covering with an electric warmer band for hyperthermia $(2 \mathrm{~h}$ at a time, twice daily, maintaining the temperature at approximately $45^{\circ} \mathrm{C}$ ) and liquid nitrogen cryotherapy (one session every 2 weeks) were applied. Cryotherapy using repeated freeze-thaw cycles was applied directly to the verrucous granuloma lesion with a cotton swab. Liver and kidney 

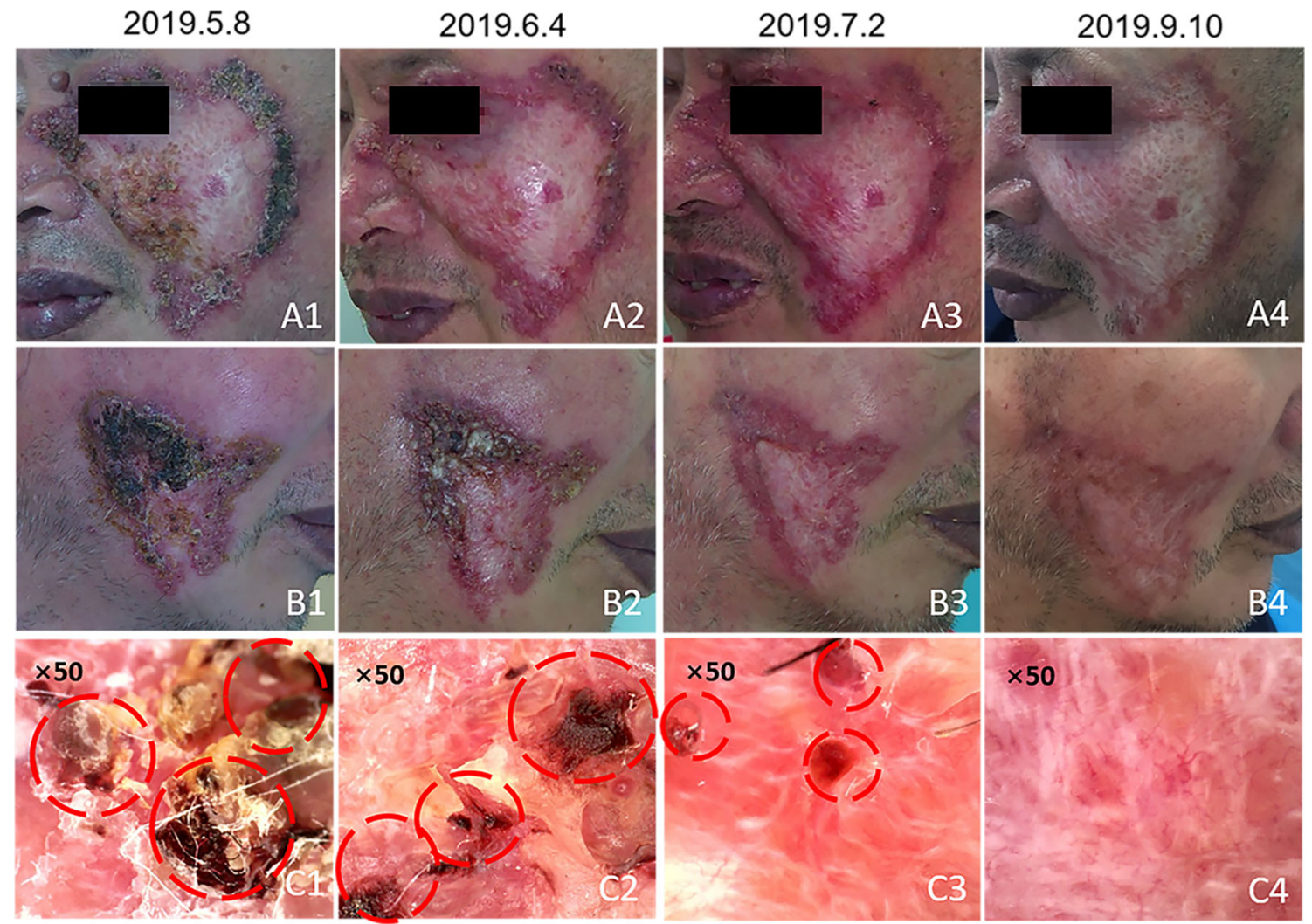

Fig. 1 Clinical manifestation of the patient observed for the first time and at follow-ups. The patient had developed multiple verrucous plaques for 8 years $(\mathbf{a} 1, \mathbf{b} 1)$. After

4 months of treatment, the lesions significantly improved (a2-a4, b2-b4). The blackish-red dot sign (red circles) gradually disappeared during the treatment $(\mathbf{c 1 - c 4})$

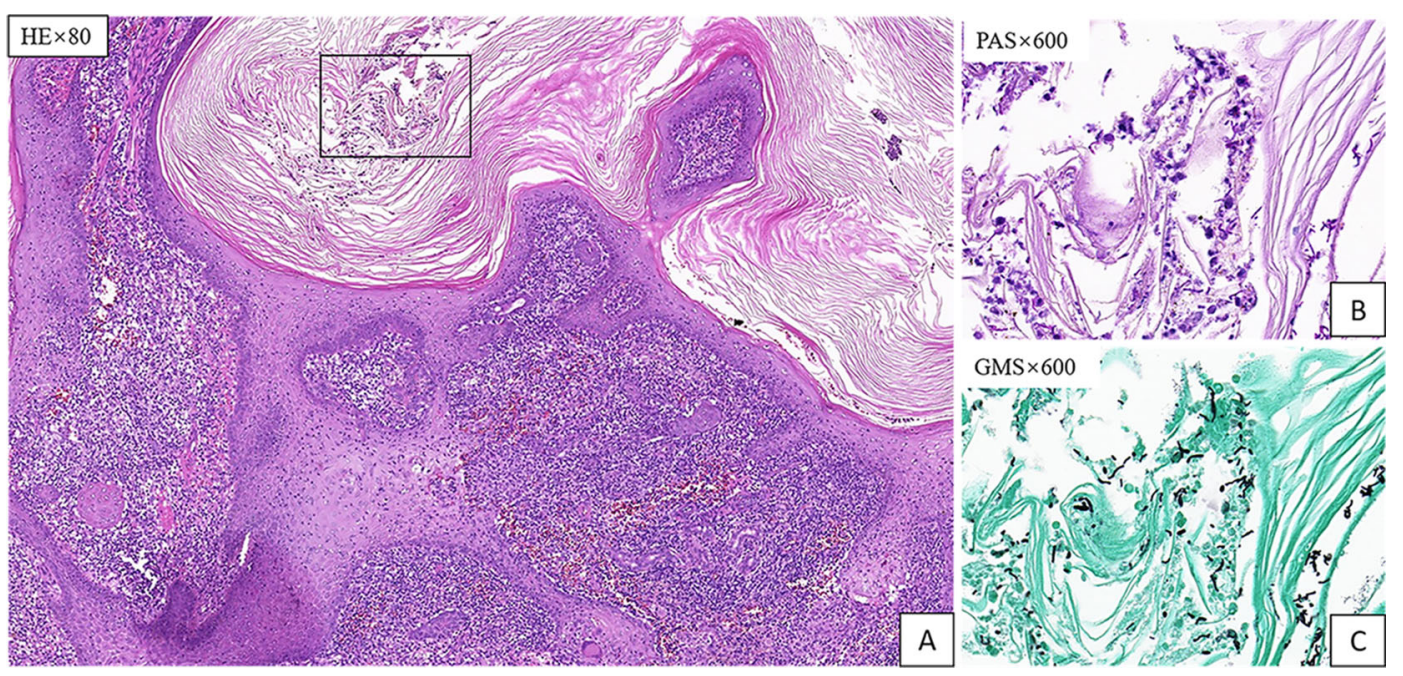

Fig. 2 Pathology of the biopsy showed dense neutrophilic infiltration and the formation of granuloma (a) and abundant short hyphae and yeasts at high power (b PAS stain, $\mathbf{c}$ GMS stain) 
function examinations every 2 weeks were within the normal limit. The patient achieved a complete response within 4 months of followup (Fig. 1a2-a4, b2-b4). The blackish-red dots gradually disappeared during the treatment (Fig. 1c1-c4). The therapeutic course is summarizedas Fig. 3.

\section{DISCUSSION}

Candida spp. is an opportunistic pathogen, widely found in soil, water sources and wild bird droppings [5]. It can also be found in healthy human skin, the vagina, oral cavity and digestive tract, causing local or systemic infections with decreased body resistance or change in the local environment. The incidence of Candida infection has been increased drastically along with a more widespread pathogenic agent spectrum because of the use of broad-spectrum antibiotics, glucocorticoids, immunosuppressive agents and the extensive implementation of interventional diagnosis and treatment such as intravenous catheterization [1]. Studies have reported that $C$. albicans remains the leading pathogenic agent of clinical primary or secondary infections. Similarly, the number of infections caused by non-Candida albicans, especially C. glabrata and C. tropical, is also increasing [2-4].

Candidal granuloma, first reported by Hauser and Rothman in 1950, is a rare type of cutaneous candidiasis. There are two clinical types of deep cutaneous candidiasis: Hauser-Rothman and Busse-Buschke [6]. The typical lesions are presented as inflammatory papules, nodules, blisters, pustules, abscesses and plaques covered with thick yellow-brown scabs [6]. The most commonly affected populations are infants and children with immunocytopenia or lymphocytopenia and adults with long-term use of immunosuppressants or glucocorticoids. $C$. albicans is reported as the main pathogen of candidal granuloma [1]. C. tropicalis mainly causes superficial and systemic infections, such as oral candidiasis, candida vaginitis, onychomycosis and candidemia [4]. Candidal granuloma is an extremely rare manifestation of C. tropicalis infection.
Systemic antifungal medication is the firstline therapy for candidal granuloma. However, the longer course of treatment, drug resistance and concerns about side effects may cause dissatisfaction in patients. Initially, the lesion was treated with oral terbinafine for 5 months as well as oral itraconazole for 11 months. Although the results of microscopy and fungal culture were negative, verrucous skin lesions slightly improved. Synergism of terbinafine with itraconazole is presumed to be due to the combined effects of the drugs on different stages of the ergosterol biosynthesis pathway. Considering the synergism effect observed in Candida and other strains such as Mucor irregularis, Malassezia and Cryptococcus [7-10], we highly recommend treating the skin lesion with itraconazole and terbinafine. Furthermore, hyperthermia and liquid nitrogen cryotherapy also were suggested for a potentially better curative effect and shorter duration of treatment.

Hyperthermia and cryotherapy are extensively applied for the treatment of dermatologic infections [11]. Thermotherapy with its various formations is reported to be beneficial for bacterial and fungal infectious diseases, such as mycobacterial disorders, sporotrichosis and chromoblastomycosis $[11,12]$. The application of ALA-PDT in the treatment of candidal infections has also been reported [13-15]. In general, the use of an electric warmer band compared with ALA-PDT and in situ photoimmunotherapy is much cheaper and convenient. Similarly, cryotherapy is also applicable for infections because of an enhancement of immunocompetence and direct toxic effects on microbes. Liquid nitrogen cryotherapy is not only suitable for warts, but also deep cutaneous infections, such as chromoblastomycosis, cutaneous leishmaniasis and even candidal keratitis $[11,16]$. There is limited experience with systemic itraconazole and terbinafine with the local application of hyperthermia and cryotherapy in the treatment of candidal granuloma.

Furthermore, the unique dermoscopic blackish-red dot sign observed in our case disappeared along with the effective antifungal therapy. Similar findings have been reported in 


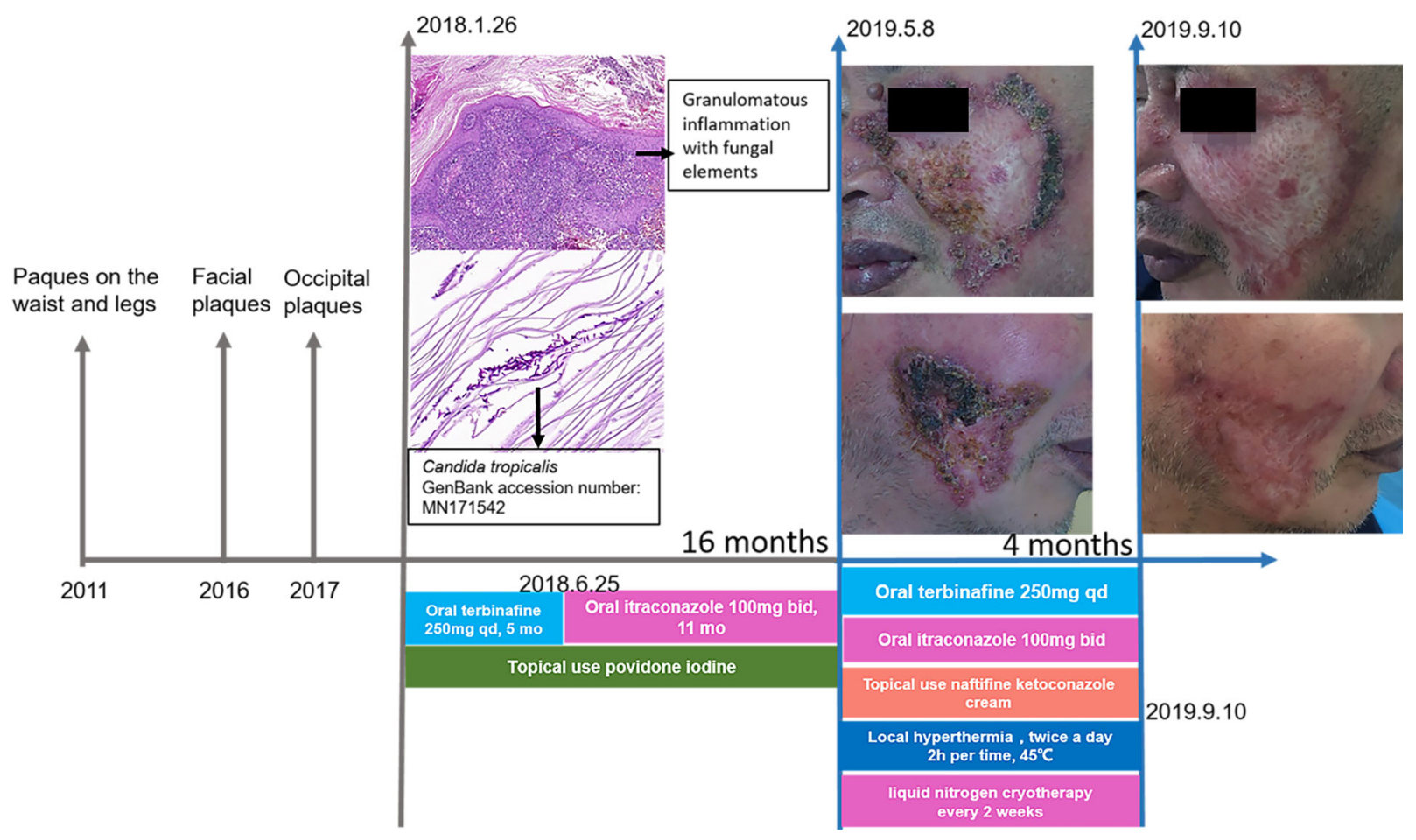

Fig. 3 Detailed time course of the patient's clinical course and therapeutic regimen

cases of chromoblastomycosis, sporotrichosis and Talaromyces marneffei infections $[12,17-20]$. Those dots consisted of small hematic crusts, cellular debris and fungal structures [12]. This sign mainly represented the products of transepithelial elimination of the inflammatory response [21]. Therefore, we concluded that the blackish-red dot sign may be an indication for chronic infectious skin diseases, including candidal granuloma.

This study presents a case of refractory candidal granuloma caused by $C$. tropicalis, successfully treated with itraconazole and terbinafine in combination with hyperthermia and cryotherapy. For refractory candidal granuloma, the newer combination therapy can be helpful. Furthermore, the blackish-red dot sign observed under dermoscopy could be a prominent marker to evaluate the efficacy of the treatment.

\section{CONCLUSIONS}

The newer combination therapy of itraconazole and terbinafine can be established for refractory candidal granuloma that failed to respond to antifungal monotherapy. For a better curative effect and shorter duration treatment, hyperthermia and cryotherapy can be regarded as cost-effective adjuvant therapy. Also, we presumed that the gradual resolution of the blackish-red dot sign could be a prominent marker to evaluate the efficacy of the treatment. However, further research is needed to confirm this phenomenon.

\section{ACKNOWLEDGEMENTS}

We thank Dr. Sushmita Pradhan from the Department of Dermatovenereology, West China Hospital, Sichuan University, for her contribution to reviewing and editing the manuscript. We also thank the patient for his valuable support and participation. 
Funding. This work was supported in part by the National Natural Science Foundation of China (Grant 81773343), and The Rapid Service Fee was funded by the authors.

Authorship. All named authors meet the International Committee of Medical Journal Editors (ICMJE) criteria for authorship for this article, take responsibility for the integrity of the work as a whole, and have given their approval for this version to be published.

Authorship Contributions. Heli Yang and Xiaoxi Xu contributed equally to this study and are co-first authors.

Disclosures. Heli Yang, Xiaoxi Xu, Xin Ran and Yuping Ran have nothing to disclose.

Compliance with Ethics Guidelines. Informed written consent was obtained for the patient to publish the article and their images.

Data Availability. All data generated or analyzed during this study are included in this published article.

Open Access. This article is licensed under a Creative Commons Attribution-NonCommercial 4.0 International License, which permits any non-commercial use, sharing, adaptation, distribution and reproduction in any medium or format, as long as you give appropriate credit to the original author(s) and the source, provide a link to the Creative Commons licence, and indicate if changes were made. The images or other third party material in this article are included in the article's Creative Commons licence, unless indicated otherwise in a credit line to the material. If material is not included in the article's Creative Commons licence and your intended use is not permitted by statutory regulation or exceeds the permitted use, you will need to obtain permission directly from the copyright holder. To view a copy of this licence, visit http://creativecommons.org/licenses/bync/4.0/.

\section{REFERENCES}

1. Cui J, Ren B, Tong Y, et al. Synergistic combinations of antifungals and anti-virulence agents to fight against Candida albicans. Virulence. 2015;6(4): 362-71.

2. Kakeya H, Yamada K, Kaneko Y, et al. National trends in the distribution of Candida species causing candidemia in Japan from 2003 to 2014. Med Mycol J. 2018;59(1):e19-22.

3. Montagna MT, Caggiano G, Lovero G, et al. Epidemiology of invasive fungal infections in the intensive care unit: results of a multicenter Italian survey (AURORA project). Infection. 2013;41(3): 645-53.

4. Zuza-Alves DL, Silva-Rocha WP, Chaves GM. An update on Candida tropicalis based on basic and clinical approaches. Front Microbiol. 2017;8:1927.

5. Shrestha SK, Fosso MY, Green KD, et al. Amphiphilic tobramycin analogues as antibacterial and antifungal agents. Antimicrob Agents Chemother. 2015;59(8):4861-9.

6. Hauser FV, Rothman S. Monilial granuloma; report of a case and review of the literature. Arch Dermatol Syphilol. 1950;61(2):297-310.

7. Barchiesi F, Araeni D, Del Prete MS, et al. Fluconazole susceptibility and strain variation of Candida albicans isolates from HIV-infected patients with oropharyngeal candidosis. J Antimicrob Chemother. 1998;41(5):541-8.

8. Scheid LA, Mario DAN, Kubica TF, et al. In vitro activities of antifungal agents alone and in combination against fluconazole-susceptible and -resistant strains of Candida dubliniensis. Braz J Infect Dis. 2012;16(1):78-81.

9. Reichert-Lima F, Busso-Lopes AF, Lyra L, et al. Evaluation of antifungal combination against Cryptococcus spp. Mycoses. 2016;59(9):585-93.

10. Schlemmer KB, de Jesus FPK, Loreto ES, et al. In vitro combination of antifungal agents against Malassezia pachydermatis. Med Mycol. 2019;57(3):324-7.

11. Doherty CB, Doherty SD, Rosen T. Thermotherapy in dermatologic infections. J Am Acad Dermatol. 2010;62:909-27.

12. Queiroz-Telles F, de Hoog S, Santos DWCL, et al. Chromoblastomycosis. Clin Microbiol Rev. 2017;30:233-76.

13. Cai Q, Yang L, Chen J. Successful sequential treatment with itraconazole and ALA-PDT for cutaneous 
granuloma by Candida albicans: a case report and literature review. Mycopathologia. 2018;183(5): 829-34.

14. Shi L, Luo M, Chen RW, et al. In situ photoimmunotherapy for cutaneous granuloma caused by itraconazole-resistant Candida guilliermondii. Dermatol Ther. 2016;29(5):353-7.

15. Lyon JP, Moreira LM, de Moraes PCG, et al. Photodynamic therapy for pathogenic fungi. Mycoses. 2011;54:e265-e271271.

16. Chen Y, Yang W, Gao M, et al. Experimental study on cryotherapy for fungal corneal ulcer. BMC Ophthalmol. 2015;15:29.

17. Chauhan P, Jindal R, Shirazi N. Dermoscopy of chromoblastomycosis. Indian Dermatol Online J. 2019;10:759-60.
18. Tang JQ, Zhuang KW, Ran X, et al. Chromoblastomycosis caused by Cladophialophora carrionii. Indian J Dermatol Venereol Leprol. 2017;83:482-5.

19. $\mathrm{Xu} \mathrm{XX}$, Ran X, Pradhan S, et al. Dermoscopic manifestations of Talaromyces (Penicillium) marneffei infection in an AIDS patient. Indian J Dermatol Venereol Leprol. 2019;83(3):348.

20. Lilia AG, Michelle GT, Judith DC. Chromomycosis. BMJ Case Rep. 2016. https://doi.org/10.1136/bcr2016-215391.

21. Zaias N, Rebell G. A simple and accurate diagnostic method in chromoblastomycosis. Arch Dermatol. 1973;108:545-6. 